\begin{tabular}{|c|c|c|c|c|c|c|c|c|c|}
\hline Ambriz & jusqu & $30^{\text {me }}$ & voyage & inclus & $\cdot$ & & • & \multicolumn{2}{|c|}{ I.226 repas } \\
\hline Padua & $\eta$ & $9^{\text {me }}$ & $\eta$ & $n$. & . & & . & 486 & ") \\
\hline Embla & ) & $22^{\mathrm{me}}$ & ) & ) & . & & - & I.763 & ") \\
\hline Ze Manel & 》) & $20^{\mathrm{me}}$ & ) & ) & . & & - & I.393 & $"$ \\
\hline Vega & ) & $2 \mathrm{O}^{\mathrm{me}}$ & ) & ) & $\cdot$ & & . & 2.037 & ) \\
\hline Tagus & ) & $9^{\mathrm{me}}$ & $n$ & ») & - & 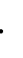 & - & $2.37^{\circ}$ & $"$ \\
\hline
\end{tabular}

Mouvement des navires entre Lisbonne et Marseille en mars 1943

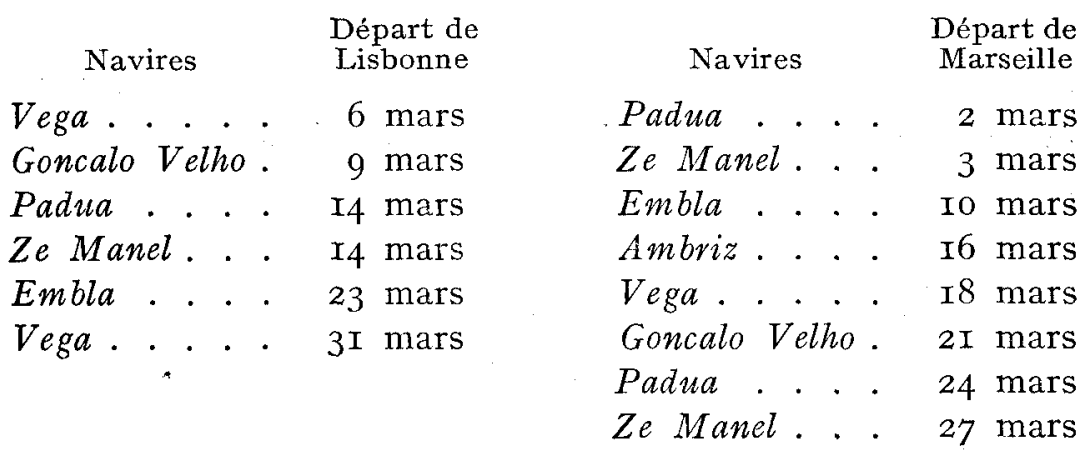

\title{
Mort de M. Marcel Reutter
}

Le Comité international a eu le profond regret d'apprendre, par sa délégation de Lisbonne, que M. Marcel Reutter, l'un des convoyeurs accompagnant les bateaux de Lisbonne à Marseille, était mort le 8 avril, après une brève maladie, à bord de l' Embla ", entre Gibraltar et Lisbonne. - Le I4 avril, les membres de la délégation de Lisbonne ont accompagné la dépouille mortelle de M. Marcel Reutter au cimetière de Sao Joao.

Le Comité international a exprimé à la famille de $\mathrm{M}$. Reutter la grande part qu'il prend à son deuil. 